\title{
Collaborative Open Strategic Planning: a Method and Case Study
}

\author{
Alireza Amrollahi ${ }^{1}$ \\ School of Information and Communication Technology, Griffith University, Southport, Australia, \\ Bruce Rowlands \\ School of Information and Communication Technology, Griffith University, Brisbane, Australia
}

\begin{abstract}
Purpose: This paper aims to show how collaborative information technology tools and a crowdsourcing model can be leveraged for the purpose of strategic planning. To achieve this objective, a formal method of Open Strategic Planning (OSP) is proposed.
\end{abstract}

Design: Based on a review of literature a set of activities, stakeholders, and governing rules are identified in the form of an OSP method. The proposed planning method is implemented in a case study of strategic planning in an Australian university. Observations by the research team, and archival records were used to ascertain the relevance of the used method.

Findings: A method for OSP is presented and assessed. The method contains four phases: preplanning, idea submission, idea refinement, and plan development. These phases cover the activities required from conceptualization to preparing and publishing the strategic plan. The findings clarify how the principles of OSP helped the organization to include more stakeholders and provided the opportunity to make the planning process transparent through use of a collaborative IT tool.

Practical implications: The study provides managers and planning consultants with detailed guidelines to implement the concept of open strategy.

Originality/value: This study is among the few to propose a method for open strategic planning based on empirical research. The study also shows how collaborative IT tools can be used for high-level organizational tasks such as strategic planning.

\section{Keywords}

Open strategy, Institutional planning, Transformation, Crowdsourcing, Information technology collaboration.

\section{Introduction}

Open Strategic Planning (OSP) is a recent paradigm in strategic planning characterised by applying the principles of inclusiveness, transparency, and the use of information technology (IT) tools (Tavakoli et al., 2015). The concept of OSP has its roots in the notion of open innovation within the information systems (IS) discipline (Chesbrough \& Appleyard, 2007; Grøtnes, 2009), and advances in social technologies known as Web 2.0 (Haefliger et al., 2011). IT tools including a crowdsourcing model are reported to play an important role in the success of OSP practice (Amrollahi et al., 2014; Dobusch, 2012; Matzler et al., 2014; Stieger et al., 2012).

The dominant perspective in strategic management research is logical positivist focusing on outcomes of strategic planning and considering strategy process as a black box (Tavakoli et al., 2015). This perspective is less efficient for OSP research, and we claim is unable to study different socio-technical process of planning, and organizational and behavioural responses. For this reason, there are calls for conducting IS/IT focused research in the area of OSP (Amrollahi \& Rowlands, 2016a; Morton et al., 2016; Tavakoli et al., 2015) using an alternative perspective.

\footnotetext{
1 alireza.amrollahi@griffithuni.edu.au

Please cite this paper as: Amrollahi, A., Amrollahi, A., Rowlands, B., \& Rowlands, B. (2017). Collaborative open strategic planning: a method and case study. Information Technology \& People, 30(4), 832-852.
} 
Despite the prevalence of strategic planning tools amongst managers (Kalkan \& Bozkurt, 2013), academic work and practice in the field of strategic planning has been criticized in the last two decades. In particular, Mintzberg (1994a) questioned the orthodox perspective on strategic planning, differentiating between strategic formulation and strategic implementation. Mintzberg (1994b) also introduced the notion that there is an information barrier between planners and implementers relating to the fallacy of detachment, i.e. the assumption that planners should be divorced from operations for the sake of objectivity, hindering the planning process. These comments started a new era of transformative strategic planning research (Wolf \& Floyd, 2013) focusing on the role of middle managers (Jarzabkowski \& Balogun, 2009; Wooldridge et al., 2008), decentralization of strategic planning (Aldehayyat \& Al Khattab, 2012; Phillips \& Moutinho, 2000), and the creative facilitator role for planning departments (Grant, 2003). These transformations from the viewpoint of academia concerning participation and transparency in strategic planning led to the development of the so-called OSP approach. The study proposes a formal method for collaborative strategic planning specifying the steps to be taken, and the stakeholders responsible for each phase. IT tools and a crowdsourcing model are leveraged to achieve this aim.

Although formal methods of strategic planning have been studied and developed to a lesser extent in recent years (Wolf \& Floyd, 2013), there are still calls for step-by-step guides to planning for practitioners (Galbreath, 2010; Papke-Shields et al., 2002). The need for formal methods is highlighted to an even greater degree when it comes to the new concept of OSP that is less known to practitioners and is in need of identifying a series of sequential actions. The current body of literature, however, has focused more on the conceptual and theoretical aspects of strategic planning, with a few case studies of implementation, and the practices have been less generalized to planning methods or processes. The present study focuses on planning methods and process, and through a review of the literature proposes a formal method of collaborative strategic planning. This planning method has been applied and the results are reported in a case study.

The rest of this paper proceeds as follows. First, it considers the background to research on strategic planning, the crowdsourcing model, and the concept of OSP. The proposed method of OSP is then explained through its various components. The research approach is explained and the case is introduced in section 4 . Section 5 contains the results of case analysis, potential challenges, and contributions for academia and practice. Section 6 concludes the paper and explains how the research aims were achieved.

\section{Research background}

\subsection{Strategic Planning Models and Methods}

Strategic planning is defined as "a disciplined effort to produce fundamental decisions and actions that shape and guide what an organization (or other entity) is, what it does, and why it does it” (Bryson, 2011, p. 6). This concept was primarily introduced with Drucker's notion of "management by objective” (MBO) (Drucker, 1954) and is still of great importance among academics (Wolf \& Floyd, 2013). The importance of strategic planning efforts are more highlighted in the context of public organizations (Tan \& Artist, 2016) especially for the purpose of education (Woods et al., 2016).

Among the many different areas studied in the strategic planning literature, formal methods of strategic planning can be found dating back to the early 1970s (McConnell, 1971). Although formal methods of strategic planning have featured less frequently in research studies since 1994 and the dynamic capabilities of the firm and contextual elements have been highlighted rather more (Wolf \& Floyd, 2013), a number of papers can nonetheless be found which have developed sequential steps for the planning process (Ratcliffe, 2000; Wang et al., 2014).

Moreover, a number of tools and techniques have been suggested to facilitate the planning process, including scenario analysis (Brauers \& Weber, 1988), stakeholder analysis (Frooman, 1999), the balanced scorecard (Voelker et al., 2001), the Delphi method (Loo, 2002), ontology-based information systems (Paradies, 2010), and the Scrum method of agile software development (Cervone, 2014). Table 1 summarizes some of the formal methods of strategic planning and activities identified in each method. The review and synthesis of these formal methods helped to develop a set of activities for strategic planning proposed in this study.

$<$ Insert Table 1 around here>

The way strategic planning projects are preformed within organisations has shifted from a primarily centralized to a decentralized approach. A crowdsourcing model is one of four tools suggested for decentralization of strategic planning (Whittington et al., 2011) and is central to the method proposed in this paper. For this reason, the model is briefly introduced next. 


\subsection{Crowdsourcing}

Using the collective wisdom of a large crowd inside or outside the firm for performing organizational tasks has always been a beneficial approach for organizations (Ranard et al., 2013; Tarrell et al., 2013). However, after the term crowdsourcing was first introduced by Howe (2006) as a new sourcing approach, it attracted considerable attention from both academia and practitioners. Research on different aspects of crowdsourcing started before the term itself was coined (Brändle, 2005). This approach is expected to provide an organization with broader viewpoints and make the firm more powerful in solving its problems compared to traditional approaches of outsourcing or doing the tasks in house (Howe, 2008). The model has also been used widely for academic, scientific, cultural, and commercial purposes (Choy \& Schlagwein, 2016; Graber \& Graber, 2013; Sawyer et al., 2011).

Various mechanisms of governance for crowdsourcing projects have been suggested in the literature. Pedersen et al. (2013) identified five categories of governance mechanisms for crowdsourcing projects: right incentive mechanism, managing submissions, loss of control, quality of the ideas and creating trust. Stakeholders in crowdsourcing projects have been classified as problem owners, individuals and crowds. The crowdsourcing process have also been subject of attention in the literature and required activities for conducting these projects have been classified in five groups of: preliminary, idea submission, evaluation, monitoring, and implementation activities (Amrollahi, 2015). The body of research on crowdsourcing stakeholders has been focused predominantly on stimuli for problem owners to initiate a crowdsourcing project, the motivations for individuals to participate in crowdsourcing projects and managing the dynamic behaviour of crowds to fulfil the aims of the project.

In this study, a mix of governance mechanisms identified from the literature is used for strategic planning where the quality of ideas submitted was assessed in a survey of experts within the organization, and stakeholders involved in crowdsourcing were classified. The following section elaborates on the concept of open strategy to describe how a crowdsourcing model can be leveraged for the purpose of strategic planning in an organization.

\subsection{Open Strategy}

Involving multiple stakeholders in the strategy process has been the subject of research and practice for many years. Mitroff et al. (1977) studied the benefits of staff participation in developing a plan for the year 2000 (25year plan) in the governmental sector. IBM started a strategy jam project prior to 2002 (Bjelland \& Wood, 2008; Palmisano, 2004) in which 50,000 IBM employees posted approximately 10,000 comments concerning the future plans of the company. From July 2009 to July 2010, the Wikimedia foundation also undertook an initiative in which 1,000 volunteers joined in over 50 languages to develop a five-year strategic plan for the Wikimedia foundation using a wiki (Dobusch, 2012).

In other case studies, technologies such as wiki (Kendall et al., 2008), forums (Stieger et al., 2012), social networks (Matzler et al., 2014), and jamming (Gast \& Zanini, 2012; Morton et al., 2015) have been reported for the purpose of facilitating strategic planning. The variety of IT tools used for the purpose of strategic planning, and studies on architecture of the required system (such as Liinamaa et al. (2004)) conveys the importance of paying attention to IT tools as a new dimension for OSP (Amrollahi \& Rowlands, 2016b; Tavakoli et al., 2015).

Another perspective on the open strategy concept is the extension of the body of research on group decision support systems (GDSS) and collaborative systems to the area of strategic decision making. This concept involves a group of stakeholders arriving at a consensus to deliver a consistent decision (Wu \& Xu, 2012) through synchronous or asynchronous communication (Kock \& McQueen, 1995). The GDSS concept has been used to facilitate collaboration among managers and strategic negotiations by providing anonymity and increasing the effectiveness of strategic decisions (Ackermann \& Eden, 2011; De Vreede et al., 2003; Olesen \& Myers, 1999).

Despite the early practice of open strategy, no theoretical research can be found in the literature prior to the work of Chesbrough \& Appleyard (2007), who developed a new concept based on the notion of open innovation that they called open strategy. They introduced open strategy as a concept that "embraces the benefits of openness as a means of expanding value creation for organizations. It places certain limits on traditional business models when those limits are necessary to foster greater adoption of an innovation approach” (Chesbrough \& Appleyard, 2007, p. 58). OSP is said to "widen the search for strategy ideas and improve commitment and understanding in strategy implementation” (Whittington et al., 2011, p. 535).

Another shortcoming in the area of OSP is a lack of a process view. A number of case studies have suggested high level processes for strategy formulation through stakeholders' participation. Dobusch (2012) for example suggested four phases of "preparation and staging of the strategy process, structuring organized publics, strategizing led by organized publics, and selecting, synthesizing and disseminating the results” in the case of Wikimedia strategic planning. Stieger et al. (2012) also suggested three general activities of energizing, listening 
and talking, and supporting as the components of OSP. Tavakoli et al. (2015) suggested a three phased process model, covering preparing strategy planning, forming and evaluating strategy, and implementing strategy, as part of a research-in-progress. However, to best of our knowledge, no empirical research on OSP methods can be found in the literature providing detailed steps toward preparing such a plan.

As previously explained, formal and processual methods are frequently used in strategic planning, however case studies of strategic planning focus on stakeholders undertaking each phase of strategic planning, for example Bryson (2011); Frentzel et al. (2000). Furthermore, the available literature on OSP remains silent about how to implement OSP principles in an organization. Moreover, crowdsourcing models are less focused for the purpose of strategic planning in the OSP literature and the effectiveness of using these models is not clear in the literature.

This study addresses these shortcomings by providing a processual perspective for implementing the OSP concept. To achieve this, a method for collaborative strategic planning through the crowdsourcing model is introduced. Moreover, the study focuses on the interactions between the IT artefact (planning system) and people (stakeholders) to study the social aspects of an inclusive approach for strategic planning. Finally, the method is implemented in a world-ranked top 300 university and the suitability of the proposed method is studied through research team observations. Hence, the following research aims are formulated for the current study:

Research Objective 1: To conduct an exploratory study of possible outcomes for implementing a collaborative model of strategic planning.

Research Objective 2: To develop a collaborative tool for strategic planning based on the crowdsourcing model.

The proposed method of strategic planning is intended to engage stakeholders in an online environment, and potentially foster adoption of the resultant plan among stakeholders involved in the strategy formulation process. The implementation of the model in a case study makes it possible to observe the attainability and relevance of the method, and underlying crowdsourcing model.

\section{Proposed Method of OSP}

Based on a review of the literature, a method of OSP is proposed to address the identified shortcomings of implementation: (i) a processual perspective (through a sequence of activities), (ii) identification of stakeholders in charge of each activity, and (iii) providing details on how the crowdsourcing model can be leveraged for the purpose of OSP (through the identification of a set of governing rules). A review of strategic planning methods, crowdsourcing, and open strategy helped frame the development of the open strategic planning method. As illustrated in Figure 1, the three components of method development were drafted based on a review of strategic planning methods and the crowdsourcing literature.

$<$ Insert Figure 1 around here>

First, based on the literature on crowdsourcing, an initial classification of stakeholders in the planning process was made. This classification was later updated and refined based on examples of practice and theoretical work on open strategy. Then, a glossary of planning activities was developed based on the review of literature on formal methods of strategic planning. This glossary reflects all possible activities through which a strategic plan could be developed. Later, based on the results of the review of open strategy practices and the principles of open strategy outlined in theoretical work, these activities were refined to form a final set of activities. Finally, governing rules were identified based on the crowdsourcing literature and best practices in open strategic planning. The following subsections introduce each component of the proposed OSP method.

\subsection{Stakeholders}

The method proposed for open strategic planning in this study involves five levels of organizational stakeholders in the planning process. As shown in Figure 2, the stakeholders' classification was inspired by the crowdsourcing literature but is more detailed on two categories of crowd, and problem owners to fit the context of OSP.

$<$ Insert Figure 2 around here $>$

Individual. This category of stakeholders comprises all designated stakeholders who have been selected to be included in the planning process and access the strategic plan developed. According to the organizational structure and policies and the scope of planning, this may cover various stakeholders, such as employees, customers, or community members. Various types of motivation and incentives should be considered to transform these stakeholders into an active crowd.

Crowd. This includes all designated stakeholders who agree to participate in the planning project and tender their ideas using the planning platform. Although this group of stakeholders has access to the content of the final plan, they are less involved in making decisions about its content. 
Selected Crowd. Managers select specific groups of stakeholders to perform roles such as ranking and revising ideas. This could be middle managers in the organization or employees who have a comprehensive understanding of the business context and limitations and thus are able to comment on others' ideas or transform them into more suitable and achievable ideas.

Managers. This is the highest level of the organization in charge of confirming the strategic direction and making strategic decisions. People in this group should approve the planning method, confirm the ideas to be considered in the final plan and approve the final plan. Support and involvement at this organizational level play a crucial rule in the success of the development of the strategic plan and related planning process.

Planning experts. This is the consultancy team which is in charge of the conceptual and technical development of the planning platform, based on benchmarking using similar plans, and also transforming the ideas that are approved into the final plan. These experts are required to have multidisciplinary knowledge in the areas of strategic planning and information systems to handle both the technical and managerial aspects of open strategic planning.

\subsection{Planning phases}

In order to identify a set of activities required to form the planning phases in the proposed method, the practices of OSP from the literature were reviewed. To do this, similar studies in the literature and phases or activities they proposed for OSP were reviewed. After extracting the suggested activities from the literature, they were then synthesized to form four phases of the method. In synthesizing the activities of the OSP literature, a certain level of abstraction was required to make the method applicable across all cases. For this reason some of the tasks in the literature were integrated with each other and some others were broken down to more than one phase. Table 2 illustrates the activities found in the literature, and how they relate to each phase of the proposed method.

<Insert Table 2 around here>

As shown in Table 2, the proposed method covers activities suggested in the literature. Details of each phase and their relationship to the literature are described below.

Preplanning activities. The development of a planning system (Stieger et al., 2012) and the introduction of the project (Dobusch \& Kapeller, 2013; Tavakoli et al., 2015) are highlighted as necessary parts of OSP in the literature. In this study, the pre-planning phase also entails an in-depth analysis of similar plans in context. In this analysis, both the content of the plan and the planning process should be the subject of attention. Reviewing the content of similar plans will help the planning team to develop a structure for the final plan and reviewing the process will make it possible to modify or customize the process based on previous practice.

The results of this benchmarking exercise will be presented to the managers and based on their comments; the planning team will develop a conceptual design for the planning system. This will include:

- $\quad$ The structure of the final plan

- $\quad$ The interface and questions in an idea submission form

- $\quad$ The planning scope and stakeholders in the crowd and selected crowd groups

- $\quad$ Criteria for ranking the ideas

Based on the conceptual design of the planning platform, the technical development of an online system will be initiated and the final products of this phase will be presented to the managers for their approval followed by the second phase.

Idea submission phase. The submission of strategy ideas is mentioned as part of the process in all studies reviewed in this research (Dobusch, 2012; Liinamaa et al., 2004; Stieger et al., 2012; Tavakoli et al., 2015). In the idea submission phase, designated stakeholders were asked to enter their ideas using the planning platform. Our research, however, stressed increasing participants' awareness of and motivation towards the planning project. Increasing personnel awareness can be undertaken through newsletters, workshops and direct communication. Workers' motivational factors in crowdsourcing projects are categorized in five groups: enjoyment-based motivation, community-based motivation, immediate payoff, delayed payoff and social motivation. This categorization can also be used in the context of open strategic planning as a guideline.

Idea refinement activities. The refinement phase of the planning process starts with ranking the ideas submitted by a number of people in the selected crowd group. To rank the ideas, a number of pre-identified criteria can be utilized, including: (i) how strategic the idea is; (ii) whether or not the idea will be applicable in the academic 
groups in two years' time (planning horizon); (iii) whether or not the idea could be generalized to all units of the organization. This ranking will help managers to filter ideas based on their scores. Here, the manager will rank each idea submitted as follows: accept, reject or revise. Those ideas that are marked for revision will be sent back to experts in the selected crowd group and for adaptation to provide a better fit with the final strategic plan in the business context. Ideas that are accepted and those that are revised will be sent to the next phase for the development of the strategic plan. This phase has been mentioned in previous work as analysis (Liinamaa et al., 2004; Tavakoli et al., 2015).

Plan development activities. Accepted and revised ideas form the input for the plan development phase. In this phase of the project, a group of experts in strategic planning will be asked to transform the approved ideas into a plan. It is worth noting that the structure of the final plan will already have been identified (based on the benchmarking using similar plans) and approved by managers.

Although this phase is suggested in previous studies (Liinamaa et al., 2004; Stieger et al., 2012; Tavakoli et al., 2015), details on how to develop the strategic plan has received less focus. In our method, analysis of approved and revised ideas is recommended for extracting strategic elements from the pool of ideas. Upcoming sections contain more examples for each phase. Figure 3 illustrates the proposed method for open strategic planning. The horizontal axis in this figure shows the phases of the proposed method, and the vertical axis is devoted to the various groups of stakeholders involved in each phase.

$<$ Insert Figure 3 around here $>$

\section{Research Methodology}

\subsection{Research approach}

In this study, a single case study was used to evaluate the efficiency of the proposed method when implemented in practice. The case method has been introduced as a facilitator of human knowledge generation (Flyvbjerg, 2006) helping researchers to provide descriptions and generate or test theory (Benbasat et al., 1987; Eisenhardt, 1989). The case approach was also considered useful when "the investigator has little control over events, and when the focus is on a contemporary phenomenon within some real-life context” (Yin, 2014, p. 1).

Taking into consideration (i) the research aim to propose an online and collaborative method of strategic planning, (ii) to conduct an exploratory study on the relevance and outcomes of the proposed OSP method, and (iii) the novelty of using a crowdsourcing model for the purpose of strategic planning, a case study was selected as the research approach. This approach also helped the study to investigate possible outcomes of using the proposed method when in implemented in real-life planning situation. An Australian university was selected as the unit of analysis.

\subsection{Case site}

In order to evaluate the viability of the proposed OSP method, an academic group in an Australian university was selected as the case site. This academic group had over 400 academic staff, serving over 5,000 students in four schools. The organizational structure in universities is usually one of professional bureaucracy in which the power is to some extent shared at the operational level and staff are expected to participate actively in the process of decision making (Mintzberg, 1979). Collaborative models such as crowdsourcing were recognized to be suitable for this context as they facilitate accessing collective intelligence and creative ideas from the virtual community of stakeholders (Pedersen et al., 2013).

The relatively flat organizational hierarchy and presence of well-educated and literate employees were factors which could facilitate the use of the crowdsourcing approach for strategic planning (Stieger et al., 2012). For this reason, an OSP approach was expected to fit this organizational structure and culture best. The project was introduced as an initial step towards collaborative planning with the intention that the plan should also be aligned with the long-term strategic plans of the university.

\subsection{Data collection}

Two main sources of evidence were used in the study: As the first author of this paper was involved in all four phases of the study, his observations and notes formed part of the data collected. The data and information recorded in the developed collaborative strategic planning system formed a second source of data. Referring to multiple sources helped the study to ensure veracity and dependability of the collected data (Wiredu, 2012). All academics in the group were invited to participate in the planning project and submit their ideas. These 
stakeholders also submitted their comments about the project via email in a number of occasions. The first author of this paper was also in charge of developing the planning system.

Specifically the following sources of data were obtained: (i) notes from five meetings with project sponsors (managers in the case organization) throughout the planning process (qualitative); (ii) notes taken by system developers throughout the development and prototyping process (qualitative); (iii) submitted ideas (qualitative); (iv) comments received via email from participating stakeholders throughout the idea submission (qualitative); (v) planning system statistics and log data (quantitative).

\subsection{Data analysis}

The technique used for data analysis was explanation building, a type of pattern matching in exploratory case studies. This method is based on the identification of a set of casual links to explain a phenomenon. The process starts with an initial theoretical statement and continues by comparing the findings to this statement and revising it accordingly (Yin, 2014). In this study, the process was built on the theoretical foundations provided by the literature relating to the possible effects of inclusion, transparency, and using IT tools on strategy process.

An iterative and deductive approach of data analysis was followed to find evidence supporting initial statements retrieved from the main research questions. For example an initial statement was "the developed plan as a result of the proposed OSP is of high quality". To search for evidence supporting (or opposing) this statement data referring to the implementation of each activity were scrutinised and managers' expressions during final meetings were found to be relevant to support this statement. Referring to this data led to the identification of suggestions and revision of the statement to read "inclusion of more stakeholders can potentially lead to a quality plan". Table 3 contains a number of examples of data analysis.

$<$ Insert Table 3 around here $>$

Results of this data analysis are narratively explained in the following section.

\section{The Findings and Discussion}

In our primary discussions with the top and middle managers in our case company, they expressed their need for an IT-enabled solution in long-term planning for their organization. These technologies are expected to facilitate the participation of people in various locations (university campuses) and lead to time and cost savings for the organization (through avoiding brainstorming and decision-making sessions).

\subsection{Pre-planning activities}

As an initial part of the pre-planning phase, a review of similar plans in 15 Australian universities was conducted to ascertain their approach to strategic planning, the structure of their plans, and the areas focused on. This review assisted the OSP process identify the required structure for the final plan (goals, objectives and strategies). This structure later led to the design of the idea submission forms. Finally, contrasting the content of the submitted ideas and developed plan in this study with similar plans in other universities assisted the study gaining an understanding about the robustness of the planning method (see section 5.5).

The results of this review exercise and the conceptual design for the planning system were then submitted to the managers for their comments and approval. Confirmation of the content/process and selected stakeholders by top managers helped to align the plan (at any level) with other strategies or long-term plans, as well as gaining support from top management, which is specified in the literature as an important factor leading to the effectiveness of strategic planning (Elbanna, 2008, 2009; Suklev \& Debarliev, 2012). In addition, establishing the content and participating stakeholders led to the development of a general matrix which was used as a conceptual basis for the technical development of the planning platform. This platform enabled authorized stakeholders to submit their ideas and then these ideas were refined in the same portal with different authorities. Online tools and Web 2.0 technologies are suggested to be appropriate for conducting organizational surveys as they result in benefits such as time and cost savings, better access to populations and ease of use (Sandars \& Schroter, 2007; Wright, 2005). For this reason, the project progressed with the development of a planning platform, facilitating the submission and refining of ideas. Figure 4 illustrates a data flow diagram for the strategic planning system.

$<$ Insert Figure 4 around here $>$ 
A strategy questionnaire was developed as a component of the planning system. The idea submission forms were designed to capture stakeholders' ideas about long term objectives of the organization. They also asked about approaches to achieve those objectives in the form of a strategic plan. Based on this (and in accordance with the benchmarking of best practices in ranked universities), participants were asked to enter any idea they believed would assist in reaching a specific goal, by answering the following questions "What is your idea for achieving this goal?” (objective) and "How do you think the idea could be implemented?” (strategy).

\subsection{Idea submission activities}

The idea submission activities officially started with a video message from the head of the academic group where he invited academic staff to submit their ideas for future directions of the group. Prior to the official launch, the planning approach and basic attributes of the planning platform were presented in a series of workshops to academics in the case organization.

Participants had the option either to submit information on their identity to enter a prize draw and be acknowledged or enter their ideas anonymously. They were then asked to provide their ideas in relation to four specified "areas of improvement” which were retrieved from the university's strategic plan (the plan governing the existing learning and teaching plan).

\subsection{Idea refinement activities}

In the next step, two experts were asked to provide a score for each idea on a five-point Likert scale. These experts were selected among those with high levels of experience in the academic group and were aware of contextual factors and limitations in the case organization. For this reason, their scores were expected to illustrate the quality of each idea. These scores helped the managers to filter the ideas in the next stage. Here a set of criteria were used to label the ideas as "accept”, “reject”, or "revise”. Ideas which were marked for revision were sent to another member of the community for amendment.

\subsection{Plan development}

The structure of the plan was developed based on the benchmarking of similar plans with three different levels: goals, objectives, and strategies. The top tier of this plan is the "goals" component, which is based on the four areas of improvement (identified on the basis of the governing strategic plan of the university). In the next level, the "objectives" were developed based on the participants' ideas generated in response to the first prompt in the idea submission form (ideas for achieving each area of improvement). In the lowest tier, "strategies" were developed based on participants' responses to the prompt asking for their recommendations for implementing their ideas. This is also consistent with the definitions of strategy and objective (a portfolio of actions which are agreed upon) and goals (which may be achieved by implementing the strategies) (Bryson, 2011).

To develop the strategic plan, an analysis was performed (similar to the analysis approach by Cochrane (2015)) on each aspect of the ideas submitted. Then the result was mapped with the identified levels of the plan and available goals. To perform this analysis, each idea was studied by the first member of the team, and one or a number of codes were assigned to that idea. The final list of ideas was reviewed by other team members and some codes were merged into each other or changed to better reflect a strategic theme. The relationship between the themes extracted was then developed in a map to construct the final strategic plan. In order to this, the approach used by Bryant et al. (2011) was followed and several maps were constructed relating the themes to each other and the specified goals of the organization. A sample of these constructive maps is illustrated in Figure 5.

\section{$<$ Insert Figure 5 around here $>$}

Finally, we discuss the strategic plan based on the developed constructive maps. The plan contained strategic directions for the learning and teaching department over the next two years and contained 15 objectives and 31 strategies for achieving the goals in the four areas of improvement. These objectives and strategies were grouped under four general goals retrieved from the strategic plan of the university and covered different areas of students' experience and graduate outcomes.

\subsection{Study outcomes}

Considering the number of submitted ideas, and the managers' acceptance of the quality of the formulated plan, the proposed model yielded satisfactory results. To evaluate the robustness of the ideas, the retrieved themes in the final pool of ideas (used to develop the strategic plan) were compared to the frequency of each theme in similar 
university strategic plans (already reviewed during the preplanning phase). The results of this comparison indicated that all the ideas submitted in this case corresponded to those in the benchmark results; moreover, there was no significant difference in frequency ranking or percentage. For example, the theme of "education techniques" as the most frequent theme was among the top themes in similar strategic plans.

The planning system log file and analytics system showed 3622 views by users and 27 strategy threads submitted over a period of two months. Submitted strategy ideas covered all of the areas of interest. Almost half of the submitted ideas addressed student retention and only a few (7\%) addressed the topic of "graduate outcomes". The student experience (26\%) and teaching quality (19\%) were other popular topics among the submitted ideas. The average score (during idea refinement) for the submitted ideas was relatively high (4.2 out of 5) and most (93\%) were approved for the plan development phase.

The quality of submitted ideas, and the final plan was mentioned as satisfactory during the final meetings with managers. Factors such as "covering important areas of competency”, "alignment with high-level strategies in university level”, and "attainability of the strategies" were highlighted as advantages for the developed plan. However, a number of challenges were highlighted during the strategy process, and are discussed next.

\subsection{Challenges and recommendations}

The first and most important challenge encountered in the case study was the participation rate. The submissions covered all of the pre-identified improvement areas. However, increasing the number of idea submissions widens the scope of strategy ideas (Whittington et al., 2011), and can potentially improve the effectiveness of the developed plan. For this reason increasing the number of idea submissions should always be considered as an important consideration in OSP. However, according to the literature on public participation, it is less feasible for all stakeholders to want to or be able to participate in high level strategic forums (Brackertz \& Meredyth, 2009).

This challenge has also arisen in some other case studies in which personnel were asked to participate in the planning process. These studies mentioned reasons such as inadequate self-confidence and shyness of staff (Cochrane, 2015; Eppler \& Platts, 2009; Mitroff et al., 1977). Another study considered that people who had not participated "did not feel that they were in a position to contribute to the plan" (Hjortsø, 2004, p. 671). These factors and the specific structure of the academic group could have caused this problem in this study.

Another challenge encountered during the planning process was the lack of consistency of ideas in submissions. According to the pre-developed structure of the plan in the study and the form developed for the submission of ideas, it was intended that the objectives (second level of the strategic plan) would be ascertained through the crowd's response to the first question (what is your idea?) and the strategies (third level of the strategic plan) through the crowd's response to the second question (how do you think the idea could be implemented?). Despite the rigour of the conceptual design and implementation, many participants entered responses to the questions relating to different levels of strategy. For example, in the final submissions of ideas there were general suggestions, such as "A comprehensive survey and analysis of the current student experience" and detailed ideas such as "Ensure that in-school assistance/staff is/are available for administrative, blended learning, and computer related tasks associated with teaching”. There were also various instances in which participants entered details on how to implement the idea (strategy in the current classification) as part of their ideas (objectives in the current classification). This issue was simply resolved by revising the ideas, but in future implementations, more information and guidelines on these concepts and examples for each of them may help the participants to align their ideas with the template to a greater extent.

In addition, a challenge was presented by the lack of strategic attributes in ideas, for example in the case that participants submitted ideas that could be considered short-term improvements in the work environment and thus lacking strategic value. These included ideas such as "upgrading the technological facilities for staff" or "accelerating improvements in the marking system". On the other hand, it should be noted that the evaluation of ideas in the ranking phase is an extremely subjective and context-based process. Short workshops and training materials on, for example, the concept of "strategy" and the notion of "long-term planning" may help mitigate this challenge in the future.

Furthermore, many ideas were submitted that were related to a specific domain and/or discipline. For instance, suggestions were made concerning improvements to teaching technologies which were applicable to only one specific programme. These ideas were sent for revision in the next phases and were transformed to general ideas. The challenge during idea submission showed that although using the crowdsourcing model assisted the planning project getting more people involved, stakeholders often do not present ideas in a way that can be easily included in the strategic planning process. This challenge possibly won't happen in further applications of the OSP concept as knowledge about OSP effort grows. 
Other than the aforementioned challenges, which mainly occurred during the "idea submission" phase of planning, another challenge was faced during the idea ranking and idea filtering phases. It is widely accepted that the main benefit of the open strategy approach is the opportunity to take more strategic ideas into consideration. However, participants have been reported to be disappointed or dissatisfied in similar case studies when their ideas have not been incorporated in the final strategic plan (Hjortsø, 2004; Langley, 1988; Ormerod, 2005). This should not affect the decisions of people who rank or filter ideas, resulting in the tolerance of low quality ideas as observed in some instances during this case study. Table 4 summarizes the challenges faced in the current study.

$<$ Insert Table 4 around here $>$

\subsection{Implications for research}

Considering inclusion as a key principle of open strategy, the following points can be inferred from the current study: first, the organizational structure of the institution should be considered as people operating in traditional structures may have higher levels of motivation to participate in strategic decision making compared to employees in flat organizations who have already experienced some levels of participation in high-level decision making (for example, the participation of academic staff in school committees); second, some stakeholders in traditional structures might be persuaded to participate by their managers, which is not the case in flat organizations.

Considering the specific dimensions and attributes of open strategic planning, future research should revisit various topics in relation to this specific context. Future research on the open strategy approach should specifically address the evaluation area and attempt to adapt aspects of the literature to specific dimensions of open strategy. The models and concepts already developed in IS area can be extended to OSP and benefit future studies. Specific dimensions of OSP highlighted in this study such as task type, participation and the process view should be considered. For example, this study could have implications for future research in the crowdsourcing area. While the basic model in this study was the crowdsourcing model, the participation and motivation trends could be studied in greater depth in future research.

Future studies can develop the proposed method in two ways. First, case studies can apply the method in other contexts and evaluate its relevance. Second, the model can be further developed and other potential components such as a planning system can be considered to develop a general methodology for OSP. Using a design perspective can be beneficial here as it is recommended for strategy research (Osterwalder \& Pigneur, 2013) and may further help the construction of a methodology. Finally, although the current study confirmed the utility and viability of using the crowdsourcing model for the purpose of strategic planning, the short-term effectiveness (stakeholders' interpretations) and long-term effectiveness (organizational impact) of OSP warrants future study.

\subsection{Implications for practice}

The open strategy concept (like open innovation) has been introduced as a continuum (not a binary concept) in the literature and for this reason, developing an open strategy in its pure form (with the inclusion of every possible stakeholder and complete transparency) may not be feasible for most organizations. However, even in a less than optimal case, a number of challenges could arise which hinder the application of an open strategy approach. These include conventional perceptions regarding the strategy and the central role of managers in its development. The perspective adopted here, in contrast to the contention of Whittington et al. (2011), is that the open strategy approach is not expected to destabilize strategic planners and those in consulting. This approach is even expected to provide better opportunities for consultants to shift their services to pre-planning activities (especially platform development) and develop a wider market in new small and medium-sized enterprises, which could start their strategic planning initiatives with the open strategy approach.

Using IT, as a principle of OSP, facilitated collaborative formulation of the strategic plan. As the case study was conducted in a multi-campus university with difficulties in accessing stakeholders in different geographical locations, collaborative technologies and a crowdsourcing model resulted in savings of time and cost of accessing stakeholders. This case illustrates a new application for groupware technologies having already been implemented in various areas (Robertson et al., 2001; Yoong \& Gallupe, 2001). For this reason, this study should attract the attention of practitioners aiming to develop strategic plans in multi-location organisations.

In the current study we also found the principles of transparency and inclusiveness to impact the planning process in terms of saving time and cost for planning. However, practitioners who intend to use an open strategy approach should consider different ways of increasing participation in the planning process. Comparing the participation rate in this study to that in other similar cases, it seems that there might still be a role for face-to-face communication inside the firm. In all of the cases considered here, an online tool has been utilized for strategic planning, but communication between the stakeholders, which might be expected to be lower in an academic group across four different campuses, still seems to be of considerable importance in motivating the participants. 
The role of incentives (especially monetary and payoff incentives) has also been questioned in this study: although three different types of incentive mechanisms were considered in this case, more than half of the ideas were submitted anonymously, which indicates the lack of willingness on the part of the participants to enter the prize draw or even be considered as a participant in the final plan.

Compared to previous published studies proposing a processual approach for OSP (Dobusch, 2012; Stieger et al., 2012; Tavakoli et al., 2015), the current study provides a more detailed approach and explains how each step functioned through an empirical case. Moreover, the proposed method contains information about various groups of stakeholders responsible for each activity in the strategy process - a topic not reported on in previous studies. A detailed method for collaborative strategic planning and the outcomes of this method can create a benchmark for OSP in future work. This means that practitioners can contrast their outcomes and the context of their organization and decide to choose or modify the proposed OSP method.

Practitioners can also benefit from the challenges faced in this case study and try to mitigate and/or address such challenges following certain recommendations. The main lessons learned through this case study were the significance of increasing awareness (through meetings, workshops, training sessions and online materials) and providing better criteria for ranking and filtering strategic ideas. Based on these, various areas for improvement were identified at the end of the project which could be implemented in future practice. To increase transparency, the rank and revising of ideas could be performed by the crowd (rather than the selected crowd). Beyond increasing the openness of the process, this could also result in increasing participants' engagement in future and help more stakeholders (especially those who are less likely to trigger a strategic idea) to participate.

\section{Conclusion}

This paper proposed a method for open strategic planning and reported on a case concerning the use of crowdsourcing techniques to implement open strategy. This approach helped an organization to maintain managerial supervision over the strategy process (through approval functions) whilst simultaneously widening the search for ideas. The results of implementing the proposed method indicate its potential for use in the context of other universities and similar organizations. The crowdsourcing model helped the proposed OSP method to develop phases of collaborative strategic planning and also assisted the research to identify stakeholders relevant in the strategy process.

Based on data collected during the implementation of the OSP approach, this study suggests that using an ITenabled crowdsourcing system is an appropriate tool to attract strategy ideas and refine them in the form of a plan. The use of collaborative technologies and a crowdsourcing model helped the research to implement two other principles of OSP (inclusiveness and transparency) through the means of seeking anonymity and constant communication with stakeholders. Further, the online crowdsourcing system resulted in savings of time and budget for strategic planning. Finally IT tools helped a geographically dispersed organization (multi-campus university) to improve inclusion of stakeholders in high-level strategic tasks.

The results of this study may be beneficial for future practitioners who intend to use the OSP approach. The study also highlights several questions which could be answered by future studies in the open strategy area. The study achieved its identified objectives. Firstly by exploring challenges and opportunities that may be encountered as a result of employing such an approach; and secondly, proposing a method for implementing the OSP concept in organizational settings. The proposed method is a first step toward a generic methodology for OSP.

\section{References}

Ackermann, Fran, \& Eden, Colin, 2011. Negotiation in strategy making teams: group support systems and the process of cognitive change. Group Decision and Negotiation, 20(3), 293-314.

Aldehayyat, Jehad, \& Al Khattab, Adel, 2012. Strategic Planning and Organisational Effectiveness in Jordanian Hotels. International Journal of Business and Management, 8(1), 11-25.

Amrollahi, Alireza. (2015). A Process Model for Crowdsourcing: Insights from the Literature on Implementation. Paper presented at the Australasian Conference on Information Systems: ACIS 2015, Adelaide.

Amrollahi, Alireza, Ghapanchi, Amir, \& Talaei-Khoei, Amir, (2014), Using Crowdsourcing Tools for Implementing Open Strategy: A Case Study in Education. Paper presented at the Twentieth Americas Conference on Information System (AMCIS 2014), Savannah, USA. 
Amrollahi, Alireza, \& Rowlands, Bruce. (2016a). The Effectiveness of an Open Strategic Planning Approach Paper presented at the The 20th Pacific Asia Conference on Information Systems (PACIS 2016), Chiayi, Taiwan.

Amrollahi, Alireza, \& Rowlands, Bruce. (2016b). OSPM: A Design Methodology for Open Strategic Planning. Paper presented at the Twenty-second Americas Conference on Information Systems (AMCIS 2016), San Diego, USA.

Benbasat, Izak, Goldstein, David K, \& Mead, Melissa, 1987. The case research strategy in studies of information systems. MIS Quarterly, 11(3), 369-386.

Bjelland, Osvald M, \& Wood, Robert Chapman, 2008. An Inside View of IBM's' Innovation Jam'. MIT Sloan management review, 50(1), 32-40.

Brackertz, Nicola, \& Meredyth, Denise, 2009. Community consultation in Victorian local government: A case of mixing metaphors? Australian Journal of Public Administration, 68(2), 152-166.

Brändle, Andreas. (2005). Too Many Cooks Don't Spoil the Broth. Paper presented at the The First International Wikimedia Conference, Frankfurt, Germany.

Brauers, Jutta, \& Weber, Martin, 1988. A new method of scenario analysis for strategic planning. Journal of forecasting, 7(1), 31-47.

Bryant, J, Darwin, J, \& Booth, C, 2011. Strategy making with the whole organisation: OR and the art of the possible. Journal of the Operational Research Society, 62(5), 840-854.

Bryson, John M, 2011. Strategic planning for public and nonprofit organizations: A guide to strengthening and sustaining organizational achievement (Vol. 1): John Wiley \& Sons.

Camillus, John C, 1982. Reconciling logical incrementalism and synoptic formalism—an integrated approach to designing strategic planning processes. Strategic management journal, 3(3), 277-283.

Cervone, H Frank, 2014. Improving Strategic Planning by Adapting Agile Methods to the Planning Process. Journal of Library Administration, 54(2), 155-168.

Chesbrough, Henry W, \& Appleyard, Melissa M, 2007. Open innovation and strategy. California Management Review, 50(1), 57-76.

Choy, Katie, \& Schlagwein, Daniel, 2016. Crowdsourcing for a better world: on the relation between IT affordances and donor motivations in charitable crowdfunding. Information Technology \& People, 29(1), 221-247.

Cochrane, Robyn, 2015. Community visioning: the role of traditional and online public participation in local government. Asia Pacific Journal of Public Administration, 37(1), 18-32.

De Vreede, Gert-Jan, Davison, Robert M, \& Briggs, Robert O, 2003. How a silver bullet may lose its shine. Communications of the ACM, 46(8), 96-101.

Dobusch, Leonhard, (2012), Strategy as a Practice of Thousands: The Case of Wikimedia. Paper presented at the Academy of Management Proceedings, Boston, USA.

Dobusch, Leonhard, \& Kapeller, Jakob, (2013), Open Strategy between Crowd and Community: Lessons from Wikimedia and Creative Commons. Paper presented at the Academy of Management Proceedings.

Drucker, Peter F., 1954. The practice of management: Harper \& Brothers, New York.

Eisenhardt, Kathleen M, 1989. Building theories from case study research. Academy of management review, 14(4), 532-550. 
Elbanna, Said, 2008. Planning and participation as determinants of strategic planning effectiveness: evidence from the Arabic context. Management Decision, 46(5), 779-796.

Elbanna, Said, 2009. Determinants of strategic planning effectiveness: extension of earlier work. Journal of Strategy and Management, 2(2), 175-187.

Eppler, Martin J, \& Platts, Ken W, 2009. Visual strategizing: The systematic use of visualization in the strategicplanning process. Long Range Planning, 42(1), 42-74.

Flyvbjerg, Bent, 2006. Five misunderstandings about case-study research. Qualitative inquiry, 12(2), 219-245.

Frentzel, William Y, Bryson, John M, \& Crosby, Barbara C, 2000. Strategic planning in the military: The US Naval Security Group changes its strategy, 1992-1998. Long Range Planning, 33(3), 402-429.

Frooman, Jeff, 1999. Stakeholder influence strategies. Academy of management review, 24(2), 191-205.

Galbreath, Jeremy, 2010. Drivers of corporate social responsibility: the role of formal strategic planning and firm culture. British Journal of Management, 21(2), 511-525.

Gast, Arne, \& Zanini, Michele, 2012. The social side of strategy. McKinsey Quarterly, 2, 82-93.

Ghosh, BC, \& Nee, AYC, 1983. Strategic planning-A contingency approach-Part 1. The strategic analysis. Long Range Planning, 16(4), 93-103.

Graber, Mark A, \& Graber, Abraham, 2013. Internet-based crowdsourcing and research ethics: the case for IRB review. Journal of medical ethics, 39(2), 115-118.

Grant, Robert M, 2003. Strategic planning in a turbulent environment: evidence from the oil majors. Strategic management journal, 24(6), 491-517.

Grøtnes, Endre, 2009. Standardization as open innovation: two cases from the mobile industry. Information Technology \& People, 22(4), 367-381.

Haefliger, Stefan, Monteiro, Eric, Foray, Dominique, \& von Krogh, Georg, 2011. Social software and strategy. Long Range Planning, 44(5), 297-316.

Hjortsø, Carsten Nico, 2004. Enhancing public participation in natural resource management using Soft OR—an application of strategic option development and analysis in tactical forest planning. European Journal of Operational Research, 152(3), 667-683.

Howe, Jeff, 2006. The rise of crowdsourcing. Wired magazine, 14(6), 1-4.

Howe, Jeff, 2008. Crowdsourcing: How the power of the crowd is driving the future of business: Random House.

Jarzabkowski, Paula, \& Balogun, Julia, 2009. The practice and process of delivering integration through strategic planning. Journal of Management Studies, 46(8), 1255-1288.

Kalkan, Adnan, \& Bozkurt, Özlem Çetinkaya, 2013. The Choice and Use of Strategic Planning Tools and Techniques in Turkish SMEs According to Attitudes of Executives. Procedia-Social and Behavioral Sciences, 99(6), 1016-1025.

Kendall, Susan L, Nino, Mary H, \& Staley, Shannon M, 2008. Collaborative strategic planning: a wiki application. Journal of Web Librarianship, 2(1), 3-23.

Kock, Nereu F, \& McQueen, Robert J, 1995. Integrating groupware technology into a business process improvement framework. Information Technology \& People, 8(4), 19-34.

Langley, Ann, 1988. The roles of formal strategic planning. Long Range Planning, 21(3), 40-50. 
León-Soriano, Raúl, Muñoz-Torres, María Jesús, \& Chalmeta-Rosalen, Ricardo, 2010. Methodology for sustainability strategic planning and management. Industrial Management \& Data Systems, 110(2), 249268.

Liinamaa, Kimmo, Nuutinen, Jussi A, Sutinen, Erkki, \& Vanharanta, Hannu, 2004. Collaborative Strategic Planning On-line. PsychNology Journal, 2(2), 242-254.

Loo, Robert, 2002. The Delphi method: a powerful tool for strategic management. Policing: An International Journal of Police Strategies \& Management, 25(4), 762-769.

Matzler, Kurt, Füller, Johann, Koch, Britta, Hautz, Julia, \& Hutter, Katja. (2014). Open Strategy-A New Strategy Paradigm? Strategie und Leadership (pp. 37-55): Springer.

McConnell, J Douglas, 1971. Strategic planning: One workable approach. Long Range Planning, 4(2), 2-6.

Mintzberg, Henry, 1979. The structuring of organizations: A synthesis of the research. University of Illinois at Urbana-Champaign's Academy for Entrepreneurial Leadership Historical Research Reference in Entrepreneurship.

Mintzberg, Henry, 1994a. The fall and rise of strategic planning. Harvard Business Review, 72(1), 107-114.

Mintzberg, Henry, 1994b. Rethinking strategic planning part I: pitfalls and fallacies. Long Range Planning, 27(3), 12-21.

Mitroff, Ian I, Barabba, Vincent P, \& Kilmann, Ralph H, 1977. The application of behavioral and philosophical technologies to strategic planning: A case study of a large federal agency. Management Science, 24(1), 44-58.

Morton, Josh, Wilson, Alex, \& Cooke, Louise. (2015). Opening strategy through'Jamming': exploring the process. Paper presented at the Loughborough School of Business and Economics (SBE) Doctoral Conference, Loughborough University, UK.

Morton, Josh, Wilson, Alex, \& Cooke, Louise. (2016). Open Strategy Initiatives: Open, IT-Enabled Episodes of Strategic Practice. Paper presented at the Twentieth Pacific Asia Conference on Information Systems (PACIS 2016), Chiayi, Taiwan.

Nutt, Paul C, 1984. A strategic planning network for non-profit organizations. Strategic management journal, 5(1), 57-75.

Olesen, Karin, \& Myers, Michael D, 1999. Trying to improve communication and collaboration with information technology: an action research project which failed. Information Technology \& People, 12(4), 317-332.

Ormerod, R, 2005. Putting soft OR methods to work: the case of IS strategy development for the UK Parliament. Journal of the Operational Research Society, 56(12), 1379-1398.

Osterwalder, Alexander, \& Pigneur, Yves, 2013. Designing Business Models and Similar Strategic Objects: The Contribution of IS. Journal of the Association for Information Systems, 14(5), 237-244.

Palmisano, S, 2004. Leading Change When Business Is Good. HBR's 10 Must Reads on Change, 82(12), 60-70.

Papke-Shields, Karen E, Malhotra, Manoj K, \& Grover, Varun, 2002. Strategic manufacturing planning systems and their linkage to planning system success. Decision Sciences, 33(1), 1-30.

Paradies, Simon, (2010), An approach to support strategic planning by ontological structures. Paper presented at the Fourth International Conference on Research Challenges in Information Science (RCIS 2010).

Pedersen, Jay, Kocsis, David, Tripathi, Abhishek, Tarrell, Alvin, Weerakoon, Aruna, Tahmasbi, Nargess, ... . de Vreede, Gert-Jan, (2013), Conceptual foundations of crowdsourcing: A review of IS research. Paper presented at the 2013 46th Hawaii International Conference on System Sciences (HICSS 46). 
Phillips, Paul A, \& Moutinho, Luiz, 2000. The strategic planning index: a tool for measuring strategic planning effectiveness. Journal of Travel Research, 38(4), 369-379.

Ranard, Benjamin L, Ha, Yoonhee P, Meisel, Zachary F, Asch, David A, Hill, Shawndra S, Becker, Lance B, .. . Merchant, Raina M, 2013. Crowdsourcing-harnessing the masses to advance health and medicine, a systematic review. Journal of general internal medicine, 1-17.

Ratcliffe, John, 2000. Scenario building: a suitable method for strategic property planning? Property Management, 18(2), 127-144.

Robertson, Maxine, Sørensen, Carsten, \& Swan, Jacky, 2001. Survival of the leanest: Intensive knowledge work and groupware adaptation. Information Technology \& People, 14(4), 334-352.

Sandars, J, \& Schroter, S, 2007. Web 2.0 technologies for undergraduate and postgraduate medical education: an online survey. Postgraduate medical journal, 83(986), 759-762.

Sawyer, Steve, Griffiths, Marie, Light, Ben, Lincoln, Sian, \& Kidd, Jenny, 2011. Enacting engagement online: framing social media use for the museum. Information Technology \& People, 24(1), 64-77.

Stieger, Daniel, Matzler, Kurt, Chatterjee, Sayan, \& Ladstaetter-Fussenegger, Florian, 2012. Democratizing Strategy: How Crowdsourcing Can be Used for Strategy Dialogues. California Management Review, 54(4), 44-68.

Suklev, Bobek, \& Debarliev, Stojan, 2012. Strategic planning effectiveness comparative analysis of the Macedonian context. Economic and Business Review, 14(1), 63-93.

Tan, Su Fei, \& Artist, Sarah. 2016. Strategic planning in Australian local government: A comparative analysis of state frameworks.

Tarrell, Alvin, Tahmasbi, Nargess, Kocsis, David, Tripathi, Abhishek, Pedersen, Jay, Xiong, Jie, ... de Vreede, Gert-Jan. (2013). Crowdsourcing: A Snapshot of Published Research. Paper presented at the Nineteenth Americas Conference on Information Systems, Chicago, Illinois, USA.

Tavakoli, Asin, Schlagwein, Daniel, \& Schoder, Detlef. (2015). Open Strategy: Consolidated Definition and Processual Conceptualization. Paper presented at the Thirty-Sixth International Conference on Information Systems, Fort Worth, USA.

Voelker, Kathleen E, Rakich, Jonathon S, \& French, G Richard, 2001. The balanced scorecard in healthcare organizations: a performance measurement and strategic planning methodology. Hospital topics, 79(3), 13-24.

Wang, XP, Zhang, J, \& Yang, T, 2014. Hybrid SWOT Approach for Strategic Planning and Formulation in China Worldwide Express Mail Service. Journal of Applied Research and Technology, 12(2), 230-238.

Whittington, Richard, Cailluet, Ludovic, \& Yakis-Douglas, Basak, 2011. Opening strategy: Evolution of a precarious profession. British Journal of Management, 22(3), 531-544.

Wiredu, Gamel O, 2012. Information systems innovation in public organisations: an institutional perspective. Information Technology \& People, 25(2), 188-206.

Wolf, Carola, \& Floyd, Steven W, 2013. Strategic Planning Research Toward a Theory-Driven Agenda. Journal of Management, 1-35.

Woods, Ronald, Artist, Sarah, \& O’Connor, Geraldine, 2016. Learning in Australian local government: A roadmap for improving education \& training. Commonwealth Journal of Local Governance(18), 108126.

Wooldridge, Bill, Schmid, Torsten, \& Floyd, Steven W, 2008. The middle management perspective on strategy process: contributions, synthesis, and future research. Journal of Management, 34(6), 1190-1221. 
Wright, Kevin B, 2005. Researching Internet-based populations: Advantages and disadvantages of online survey research, online questionnaire authoring software packages, and web survey services. Journal of Computer-Mediated Communication, 10(3).

Wu, Zhibin, \& Xu, Jiuping, 2012. A consistency and consensus based decision support model for group decision making with multiplicative preference relations. Decision Support Systems, 52(3), 757-767.

Yin, Robert K, 2014. Case study research: Design and methods: Sage publications.

Yoong, Pak, \& Gallupe, Brent, 2001. Action learning and groupware technologies: a case study in GSS facilitation research. Information Technology \& People, 14(1), 78-90. 
Table 1 Formal methods of strategic planning in the literature

\begin{tabular}{|l|l|l|}
\hline Source(s) & Output type & Activities/steps/stages of the planning process \\
\hline (McConnell, 1971) & $\begin{array}{l}\text { Method/model/appr } \\
\text { oach }\end{array}$ & $\begin{array}{l}\text { Determination of corporate objectives, assembling information, } \\
\text { development of planning actions, preparation of the provisional } \\
\text { plan }\end{array}$ \\
\hline (Camillus, 1982) & Framework & Analytical dimension, interactive dimension, temporal dimension \\
\hline (Ghosh \& Nee, 1983) & Approach & $\begin{array}{l}\text { Perception stage, internal appraisal, external appraisal, decision on } \\
\text { strategy, search and evaluation }\end{array}$ \\
\hline (Nutt, 1984) & Method & $\begin{array}{l}\text { Techniques linked to the stages (and the within-stage phases) of a } \\
\text { strategic planning process and decision rules to make a selection } \\
\text { from various techniques for particular applications. }\end{array}$ \\
\hline $\begin{array}{l}\text { (Brauers \& Weber, } \\
\text { 1988) }\end{array}$ & Technique & $\begin{array}{l}\text { Determination of compatible scenarios, determination of scenario } \\
\text { probabilities, determination of main scenarios }\end{array}$ \\
\hline (León-Soriano et al., \\
2010) & Framework & $\begin{array}{l}\text { Planning of the project, definition of enterprise mission statement, } \\
\text { stakeholder analysis, strategy definition, strategy implementation } \\
\text { and execution, design of indicators and targets, validation, } \\
\text { implementation, monitoring }\end{array}$ \\
\hline (Bryson, 2011) & Cycle & $\begin{array}{l}\text { Initial agreement, mandates, mission and values, internal/external } \\
\text { environment, strategic issues, strategy formulation, strategy and } \\
\text { plan review and adoption, description of the organization in the } \\
\text { future, implementation, strategy and planning process re- } \\
\text { assessment. }\end{array}$ \\
\hline (Cervone, 2014) & Method & $\begin{array}{l}\text { The kick-off, sprint planning meeting, sprint, daily Scrum, sprint } \\
\text { review meeting }\end{array}$ \\
\hline
\end{tabular}


Table 2 Planning activities in the current study and some of the open strategy practices

\begin{tabular}{|l|l|l|l|l|}
\hline The current study & Pre-planning & Idea submission & Idea refinement & Plan development \\
\hline (Stieger et al., 2012) & $\begin{array}{l}\text { Creation of } \\
\text { platform software, } \\
\text { Introduction of the } \\
\text { project }\end{array}$ & $\begin{array}{l}\text { Launch and online } \\
\text { time }\end{array}$ & $\begin{array}{l}\text { Evaluation of the } \\
\text { project }\end{array}$ \\
\hline (Liinamaa et al., 2004) & Questioning & $\begin{array}{l}\text { Analysis of } \\
\text { answers, dialogue, }\end{array}$ & Planning \\
\hline (Dobusch, 2012) & $\begin{array}{l}\text { Preparing and } \\
\text { staging of the } \\
\text { strategy process }\end{array}$ & $\begin{array}{l}\text { Structuring } \\
\text { organized publics }\end{array}$ & $\begin{array}{l}\text { Strategizing by } \\
\text { organized publics }\end{array}$ & $\begin{array}{l}\text { Selecting, } \\
\text { synthesizing and } \\
\text { disseminating the } \\
\text { results }\end{array}$ \\
\hline $\begin{array}{l}\text { (Dobusch \& Kapeller, } \\
\text { 2013) }\end{array}$ & Explaining & Defining & Analysing & $\begin{array}{l}\text { Versioning } \\
\text { and synthesizing, } \\
\text { Communicating, } \\
\text { Operationalizing }\end{array}$ \\
\hline (Tavakoli et al., 2015) & Setting-up & Generating ideas & & \\
\hline
\end{tabular}


Table 3 Sample data analysis

\begin{tabular}{|l|l|l|l|}
\hline Research question & Statement & Research data & Outcome \\
\hline $\begin{array}{l}\text { Possible outcomes for } \\
\text { implementing a } \\
\text { collaborative model of } \\
\text { strategic planning }\end{array}$ & $\begin{array}{l}\text { The developed plan as } \\
\text { a result of the } \\
\text { proposed OSP is of } \\
\text { high quality }\end{array}$ & $\begin{array}{l}\text { Meeting notes } \\
\text { (qualitative) }\end{array}$ & $\begin{array}{l}\text { According to } \\
\text { managers } \\
\text { improvement in } \\
\text { communication with } \\
\text { stakeholders can } \\
\text { improve the quality of } \\
\text { the resultant plan. }\end{array}$ \\
\cline { 2 - 4 } & $\begin{array}{l}\text { Inclusion of more } \\
\text { stakeholders can } \\
\text { potentially lead to a } \\
\text { quality plan }\end{array}$ & $\begin{array}{l}\text { Meeting notes / } \\
\text { System developer } \\
\text { notes (qualitative) }\end{array}$ & $\begin{array}{l}\text { More stakeholders } \\
\text { should be involved }\end{array}$ \\
\cline { 2 - 4 } & $\begin{array}{l}\text { Stakeholders were } \\
\text { motivated to submit } \\
\text { their ideas. }\end{array}$ & $\begin{array}{l}\text { Comments received } \\
\text { from participating } \\
\text { stakeholders } \\
\text { (qualitative) / } \\
\text { Planning system } \\
\text { statistics and log data } \\
\text { (quantitative) }\end{array}$ & $\begin{array}{l}\text { Better communication } \\
\text { was required to attract } \\
\text { stakeholders. }\end{array}$ \\
\hline
\end{tabular}


Table 4 Challenges of implementing the open strategy approach in the current case study

\begin{tabular}{|l|l|l|}
\hline Challenge & Possible roots & How to avoid/address challenges \\
\hline $\begin{array}{l}\text { Lower than expected } \\
\text { participation rate }\end{array}$ & Lack of self-confidence in participants & Increase awareness \\
\hline $\begin{array}{l}\text { Inconsistency of ideas } \\
\text { with identified structure }\end{array}$ & $\begin{array}{l}\text { Lack of consistent perception about } \\
\text { strategy levels }\end{array}$ & Guidelines and examples \\
\hline Lack of strategic value & $\begin{array}{l}\text { Lack of awareness regarding the } \\
\text { concept of strategy }\end{array}$ & Workshops and training materials \\
\hline $\begin{array}{l}\text { Lack of awareness } \\
\text { regarding current } \\
\text { practices }\end{array}$ & - & $\begin{array}{l}\text { Increase organizational awareness } \\
\text { regarding ongoing strategic } \\
\text { projects/systems }\end{array}$ \\
\hline $\begin{array}{l}\text { Discipline-based ideas } \\
\text { Tolerance in ranking and } \\
\text { filtering the ideas }\end{array}$ & - & $\begin{array}{l}\text { Revise the ideas and arrive at more } \\
\text { general notions }\end{array}$ \\
\hline
\end{tabular}




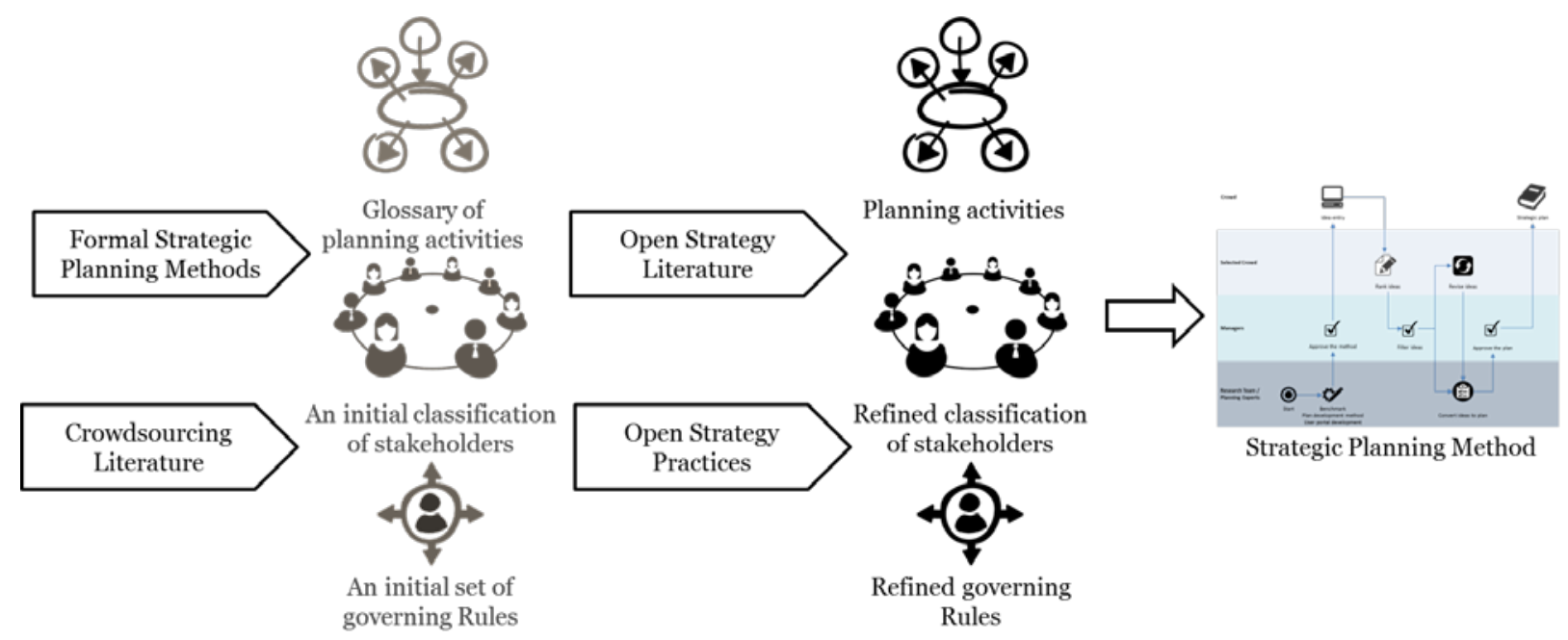

Figure 1 Method development 


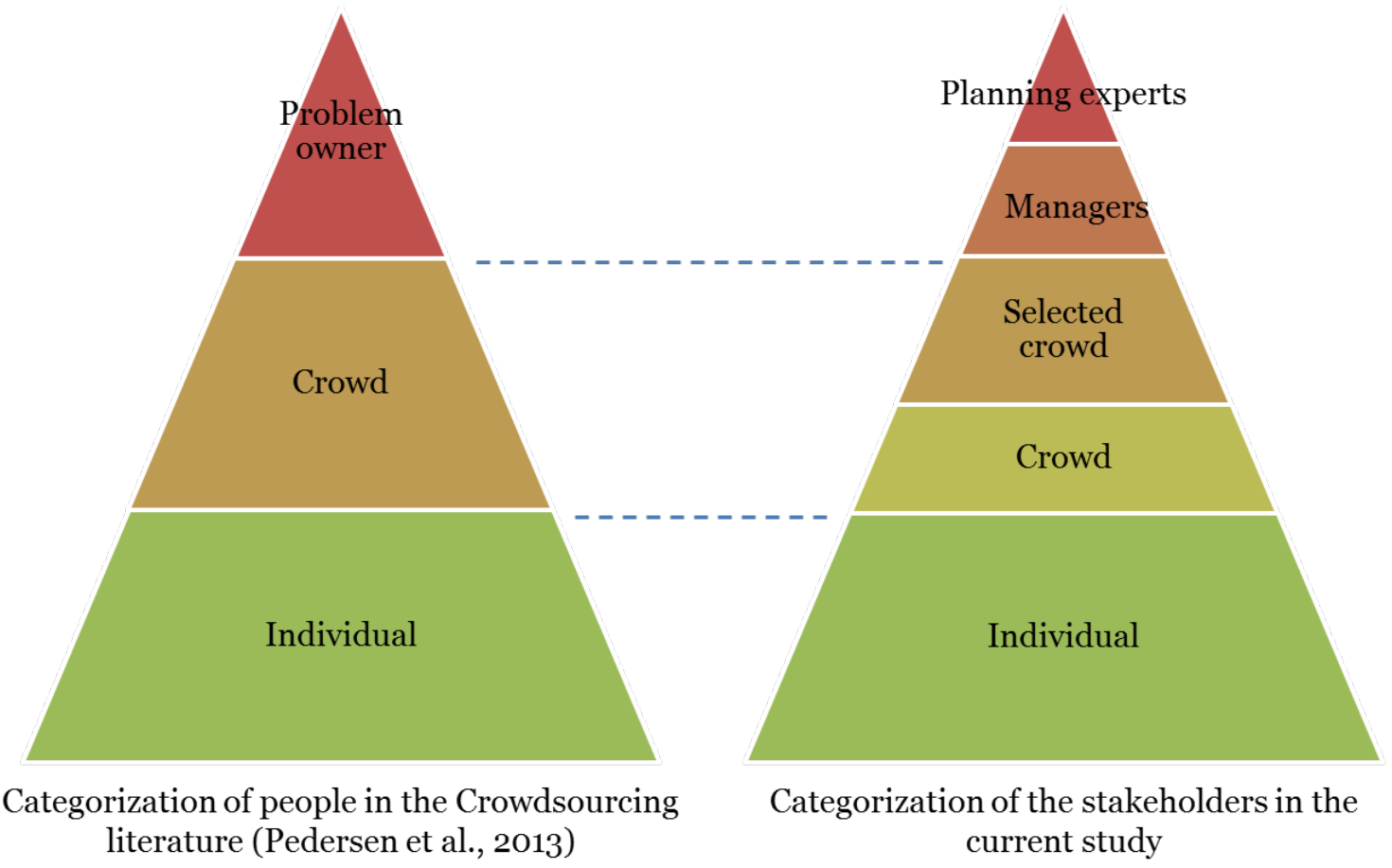

Figure 2 Contrasting categories of stakeholders in this study and the crowdsourcing literature 


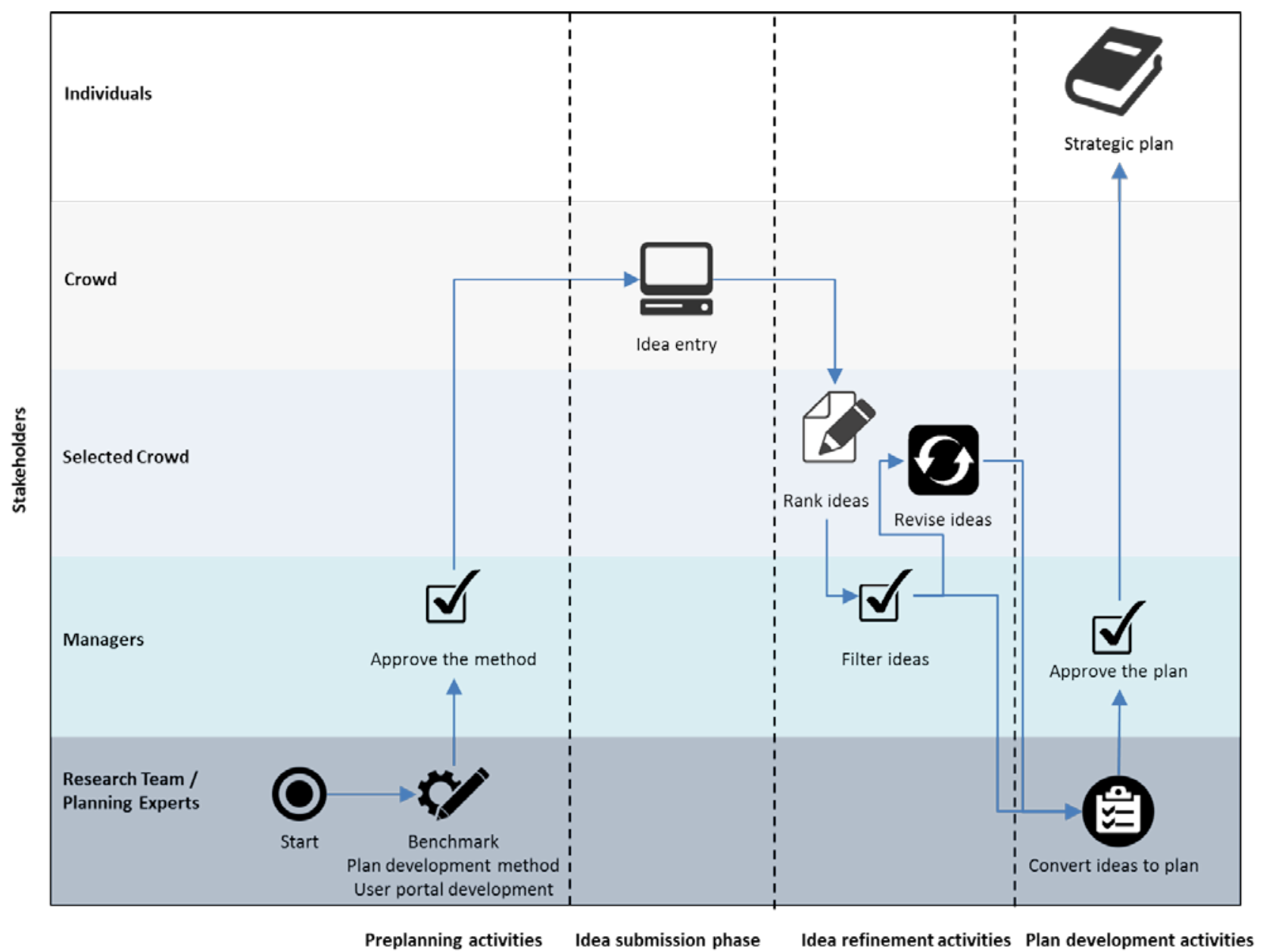

Figure 3 Proposed method for open strategic planning 


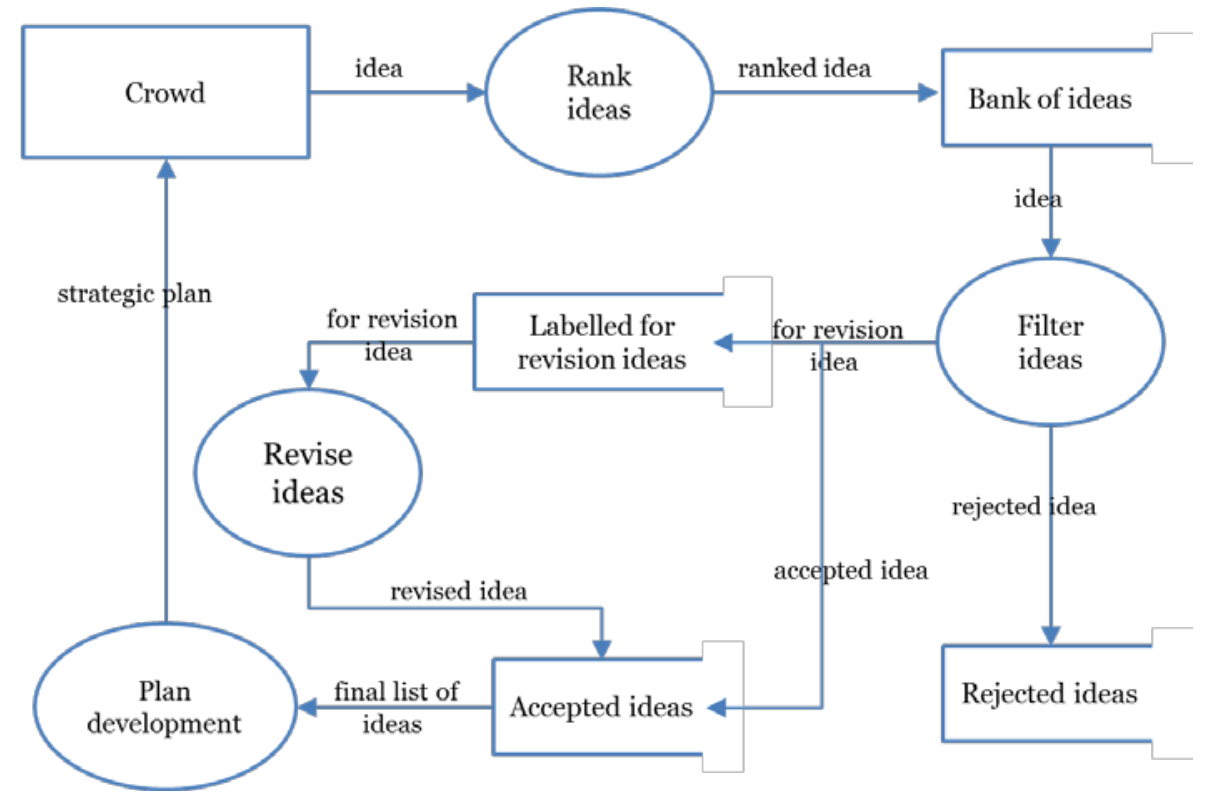

Figure 4 Data flow diagram (DFD) for the planning platform 


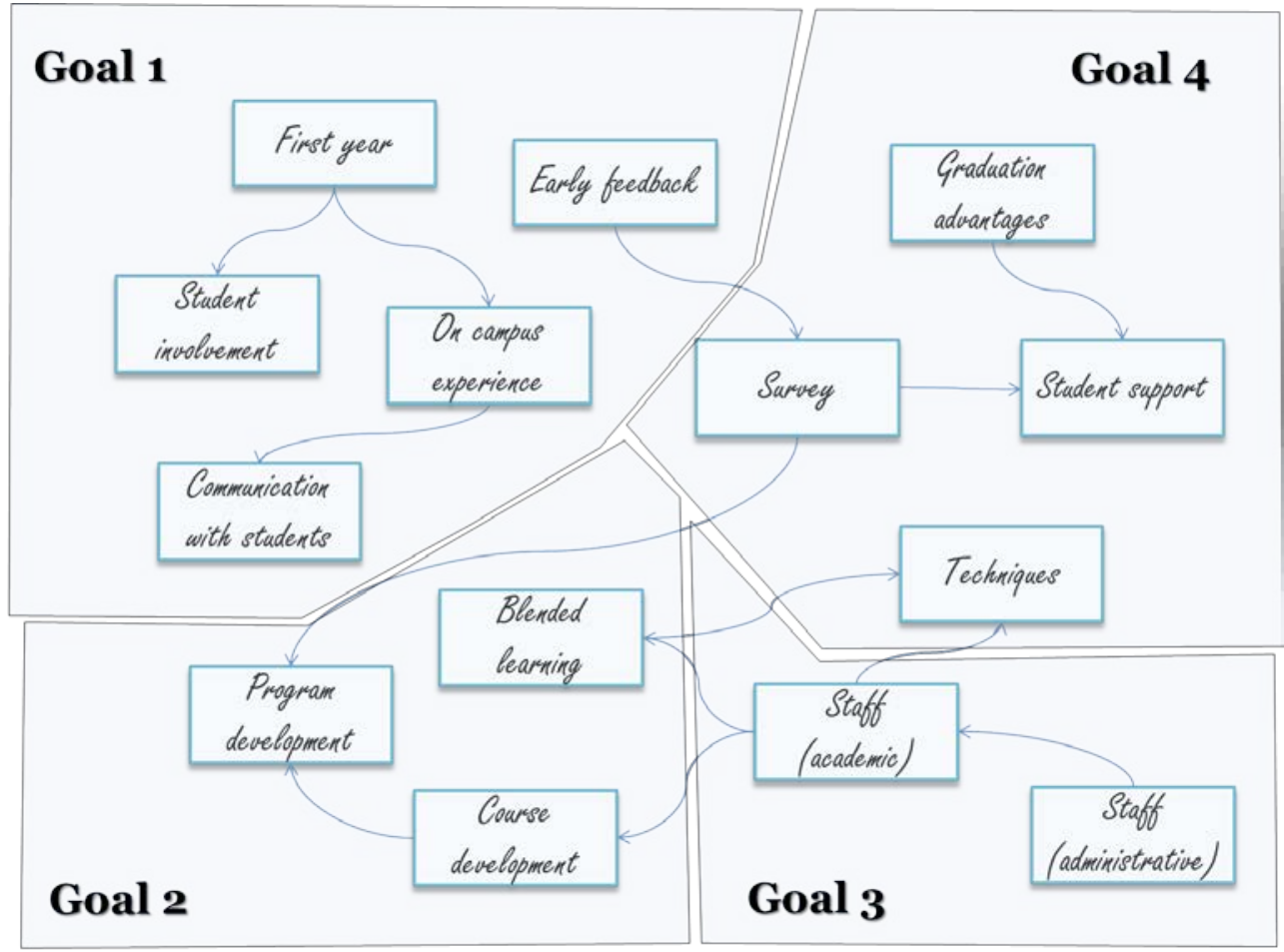

Figure 5 Sample of mapping of ideas and goals 